$7-1-2003$

\title{
Scorsese's Gangs of New York: Why Myth Matters
}

Timothy J. Gilfoyle

Loyola University Chicago, tgilfoy@luc.edu

Follow this and additional works at: https://ecommons.luc.edu/history_facpubs

\section{Recommended Citation}

Gilfoyle, Timothy J.. Scorsese's Gangs of New York: Why Myth Matters. Journal of Urban History, 29, 5: 620-630, 2003. Retrieved from Loyola eCommons, History: Faculty Publications and Other Works, http://dx.doi.org/10.1177/0096144203029005006

This Article is brought to you for free and open access by the Faculty Publications and Other Works by Department at Loyola eCommons. It has been accepted for inclusion in History: Faculty Publications and Other Works by an authorized administrator of Loyola eCommons. For more information, please contact ecommons@luc.edu. c) (i) $(9$

This work is licensed under a Creative Commons Attribution-Noncommercial-No Derivative Works 3.0 License. (C) Sage Publications 


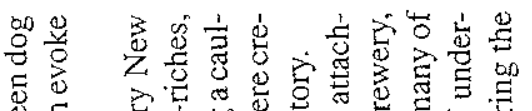

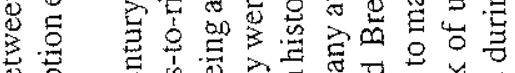

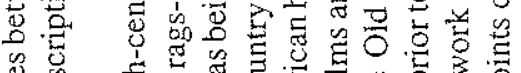

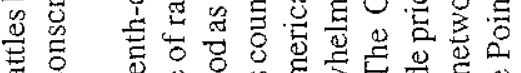

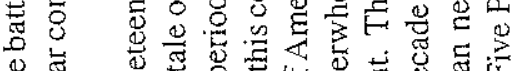

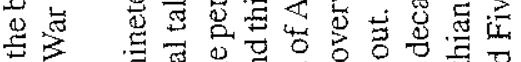

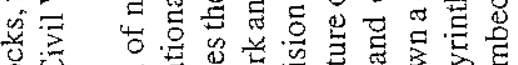

然

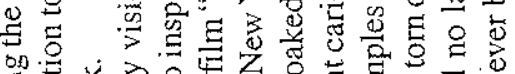
on.

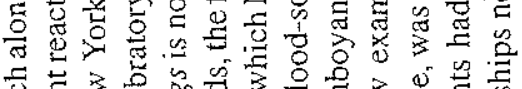

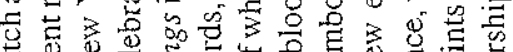

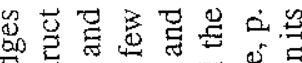

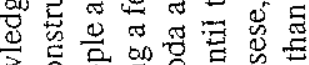

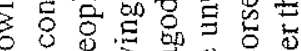

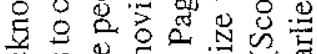

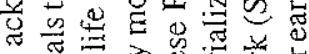

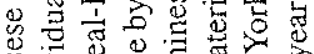

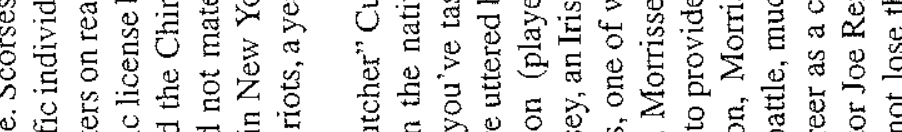

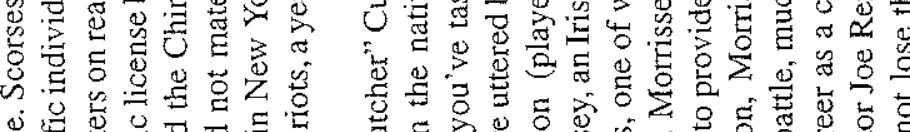

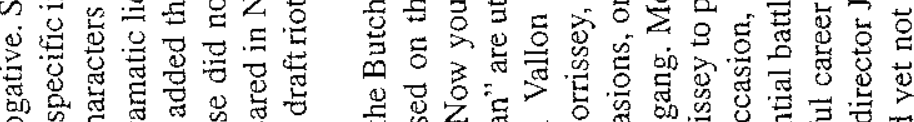

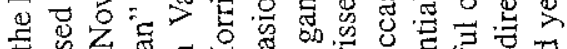

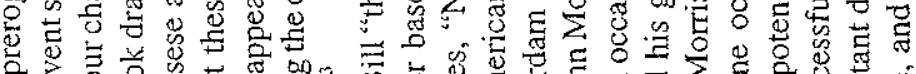

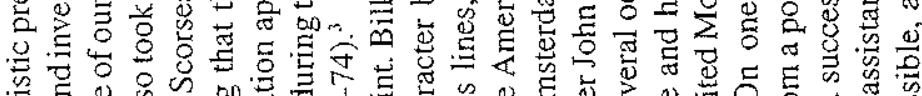

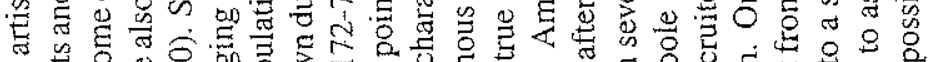

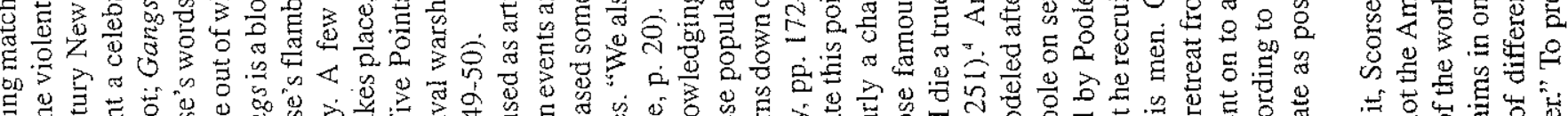

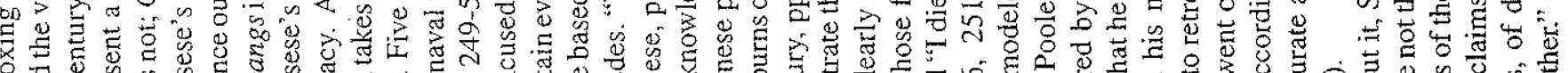

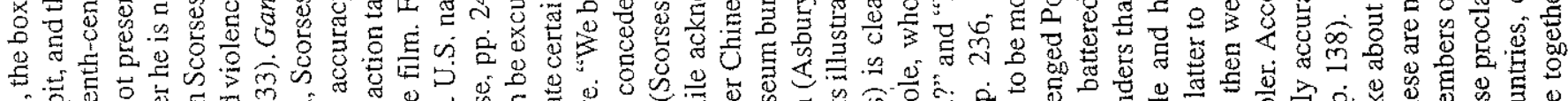

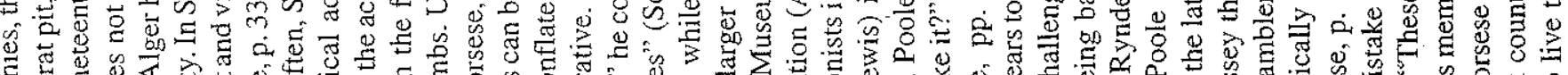

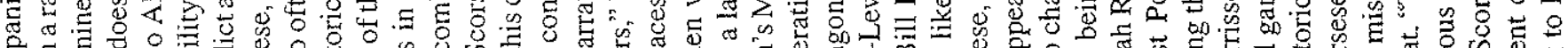

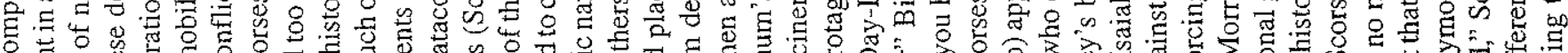

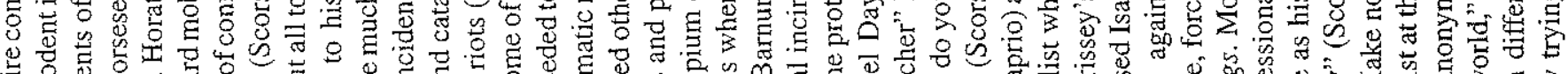

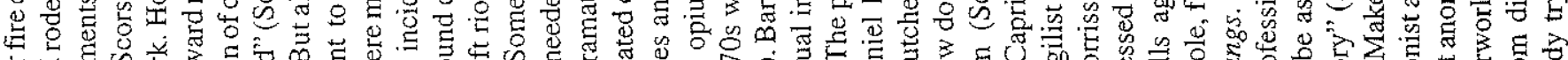

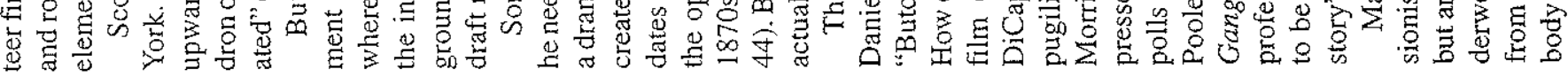

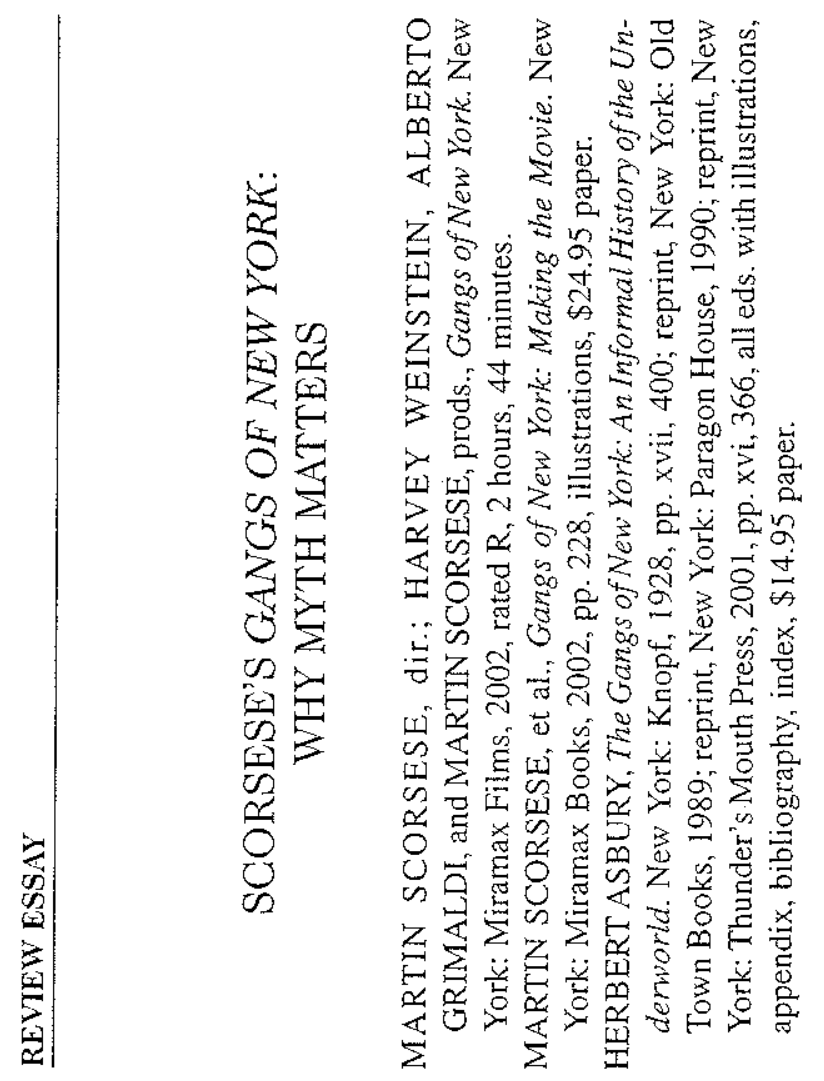

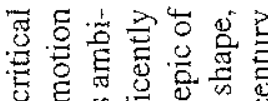

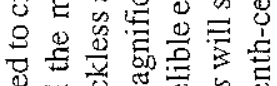

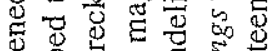

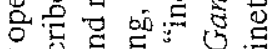
ㄴ.

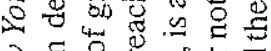
至

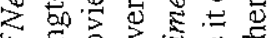

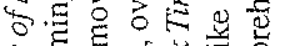
ân 830

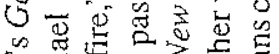

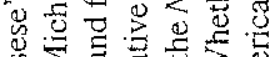

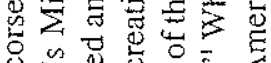

के

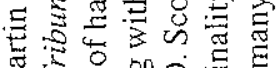

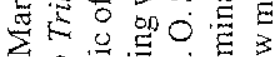

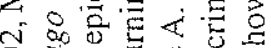

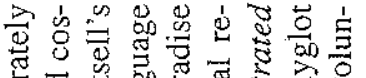

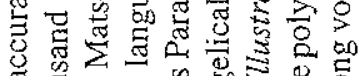
o

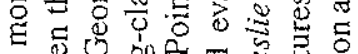
象

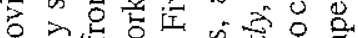

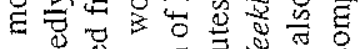

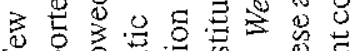
计 ن

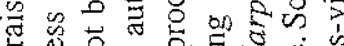

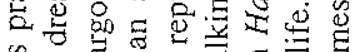

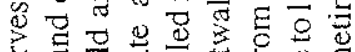

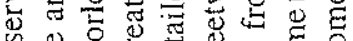
क्षे so 0 क

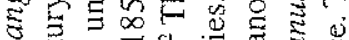
0 눙

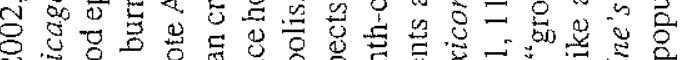

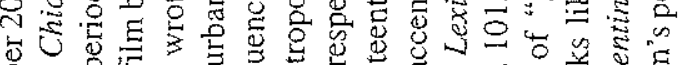

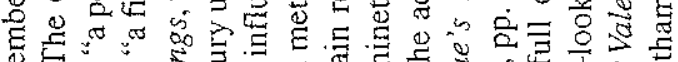

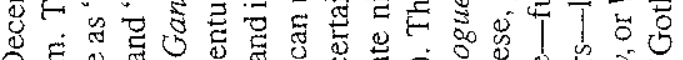

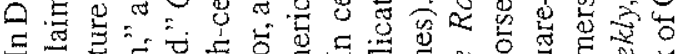

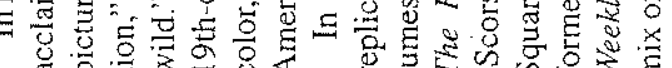

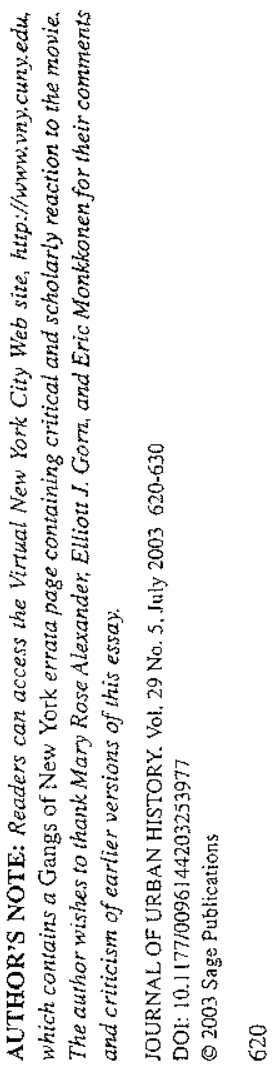




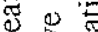

这要

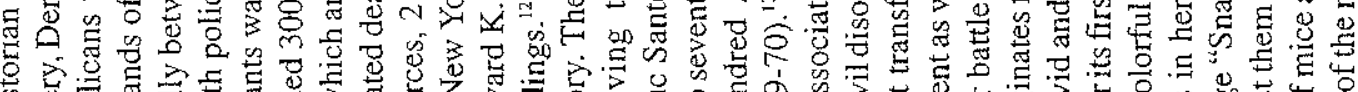

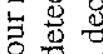

空若产

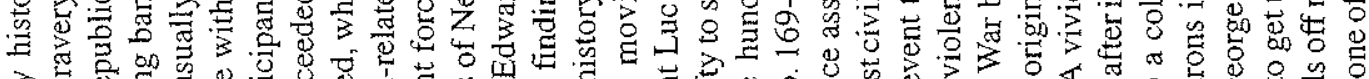

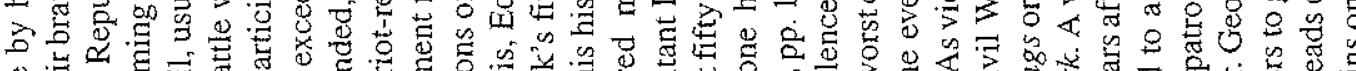

罗

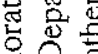

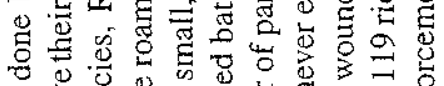

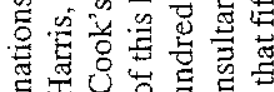

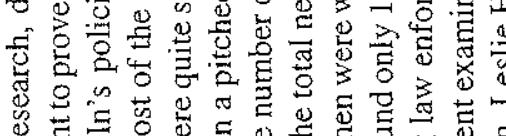

范

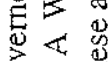

8

8

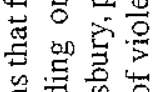

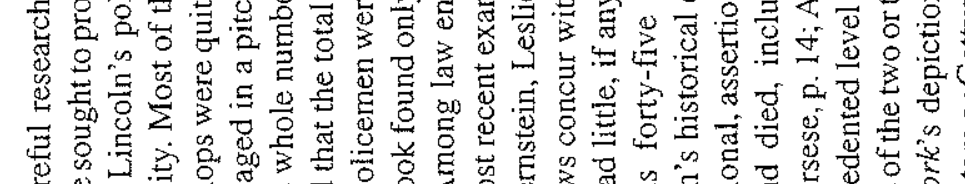

8 实

通宇

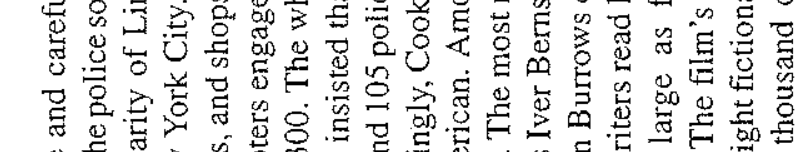

昰

峞然

3.

(5)

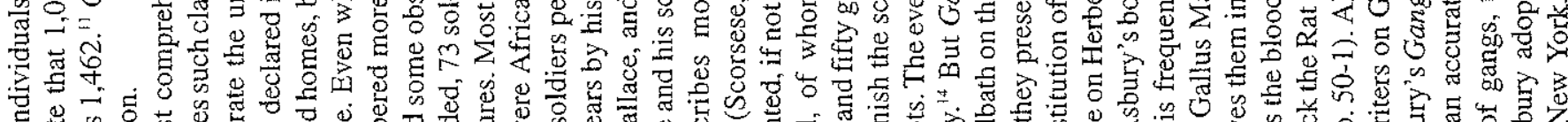

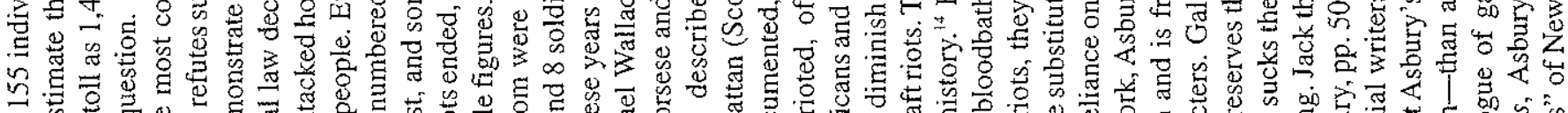

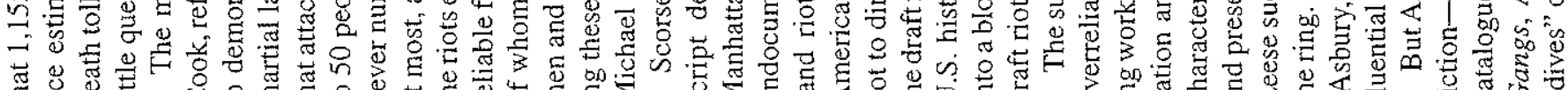

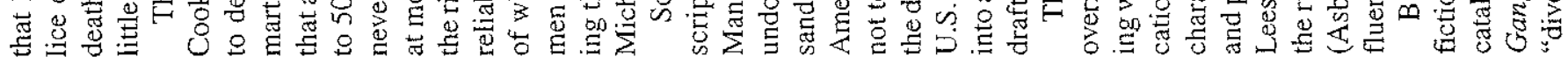

递

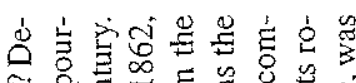

这势

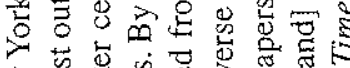

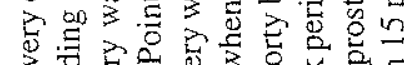

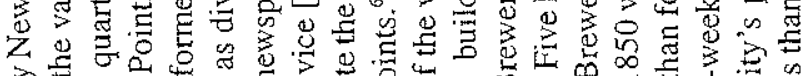

等

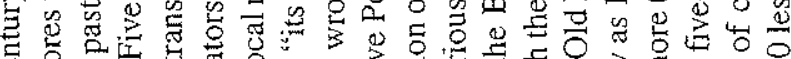

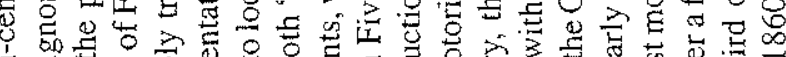

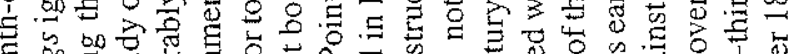

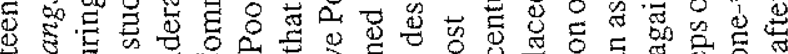

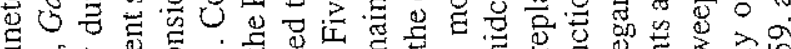

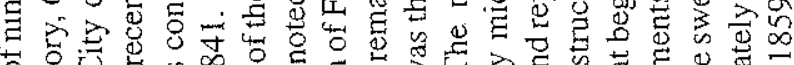

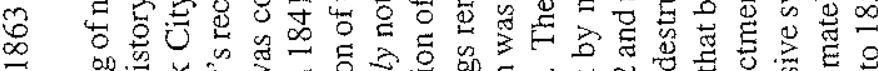

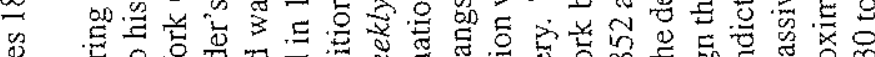

范

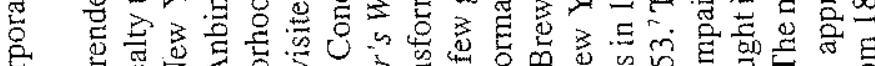

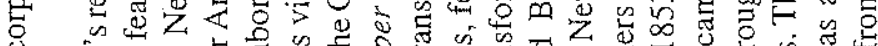

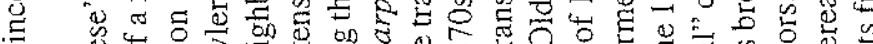

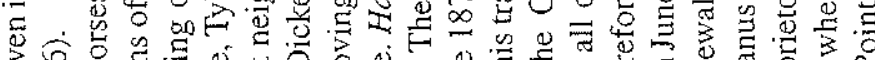

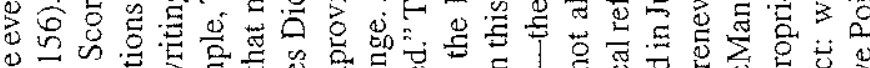

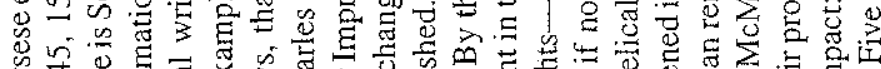

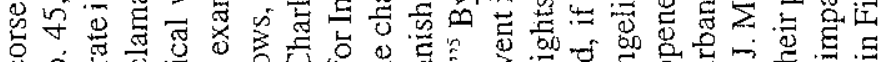

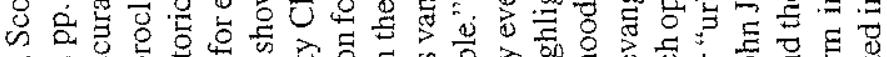
我 s

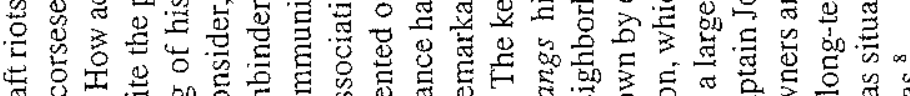

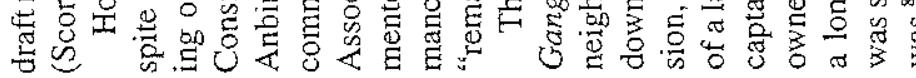

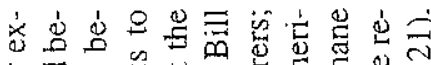

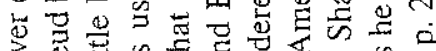

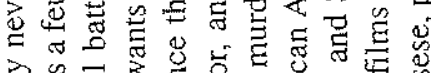

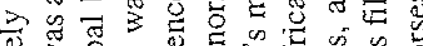

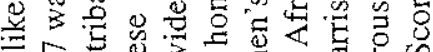

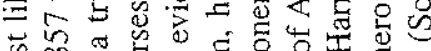

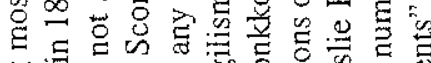
on

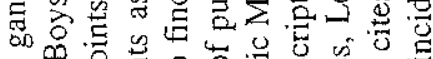

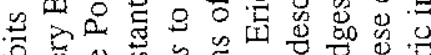

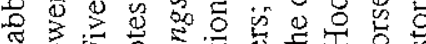

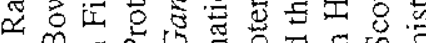

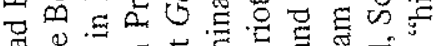
$\stackrel{8}{\circ}$ 过 Q

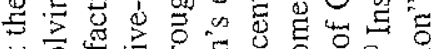

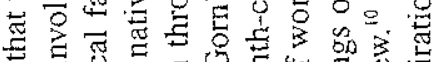
w

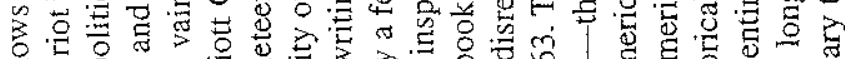

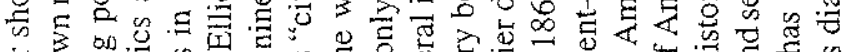

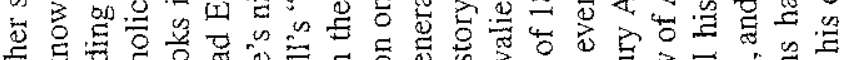

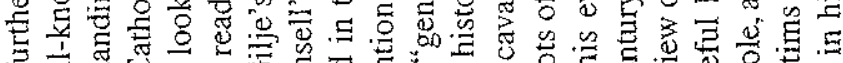
E

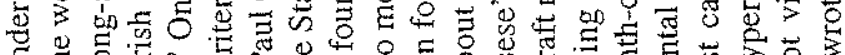

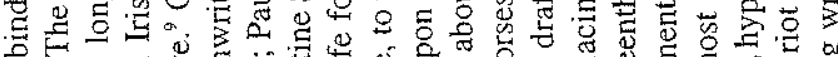

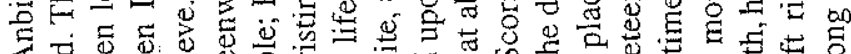

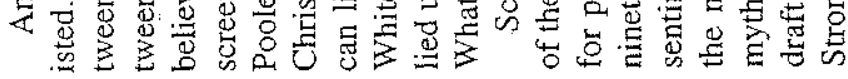




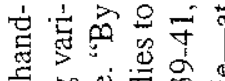
$\because$ on 0 ले

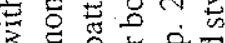

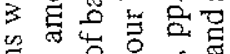

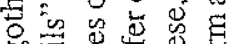

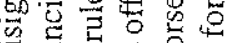

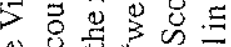

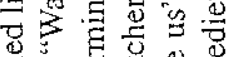

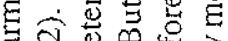
तర

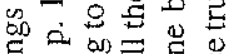

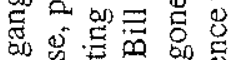
300

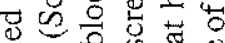

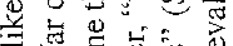

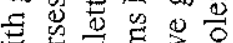

节定焉

焉总兽总

엉

颔志点亘

苟营

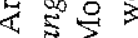

용
员焉

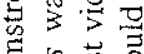

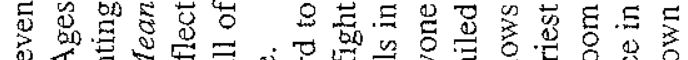

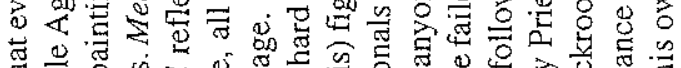

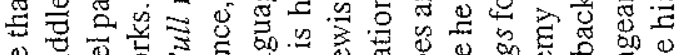

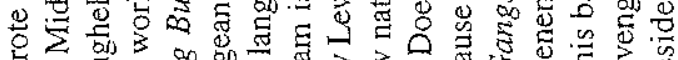

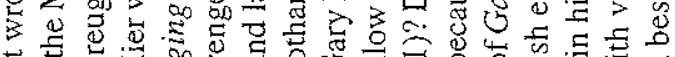

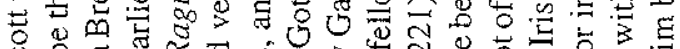

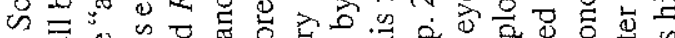

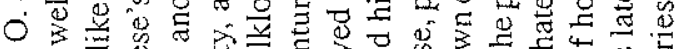

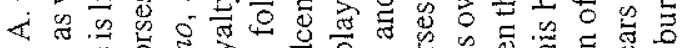

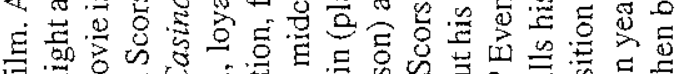

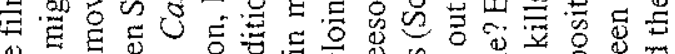

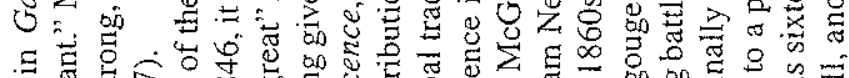

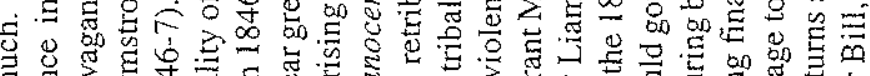

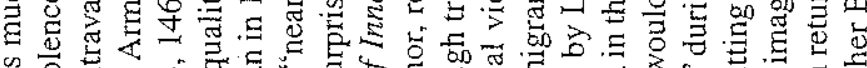
क.

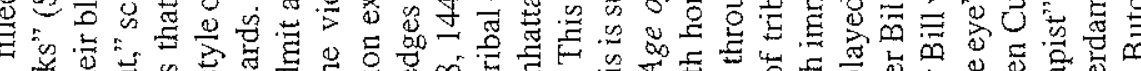

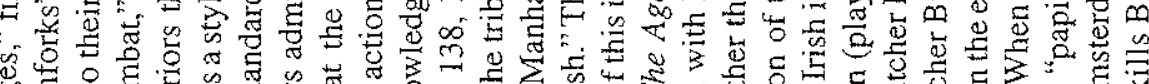

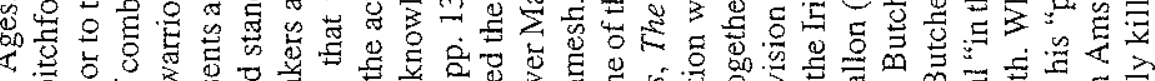

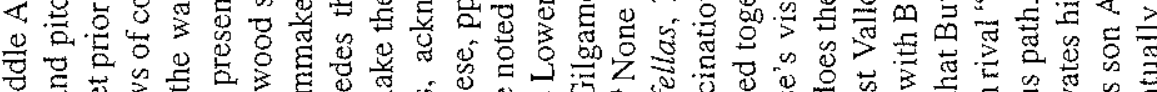

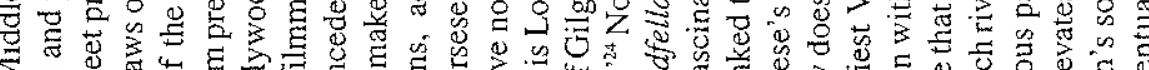

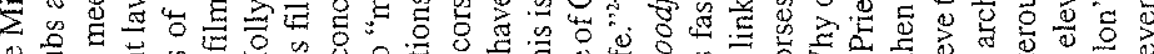

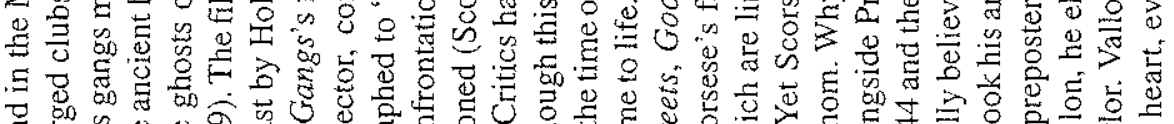

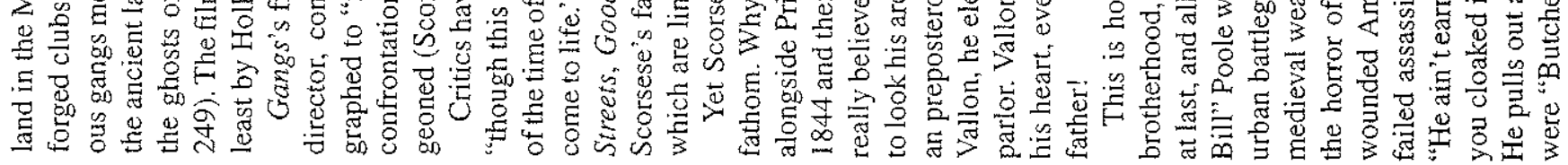

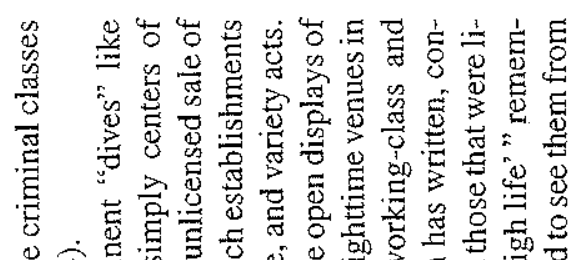

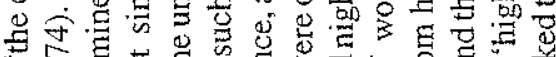

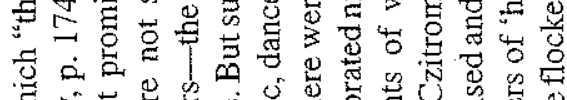

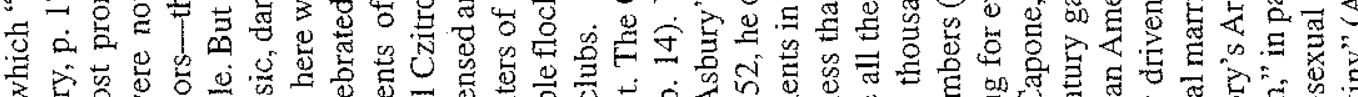

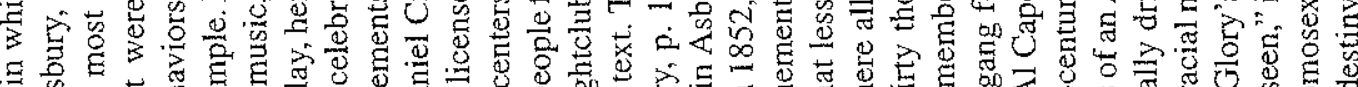
二

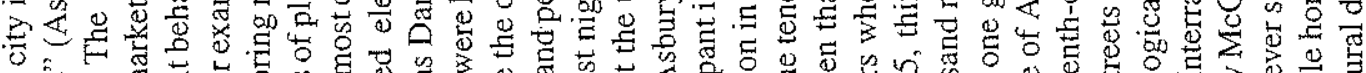

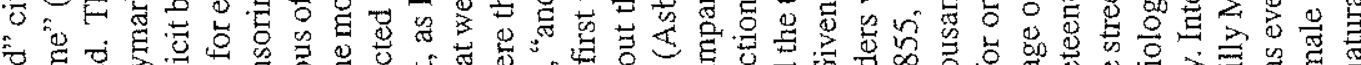

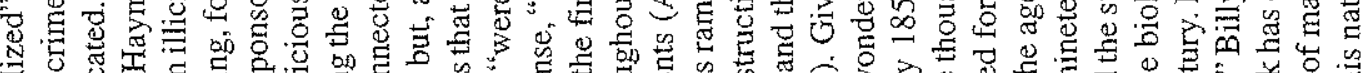

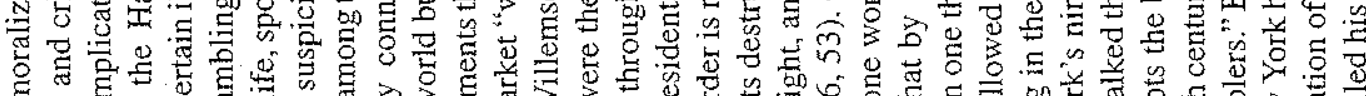

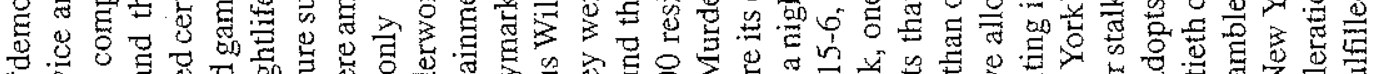

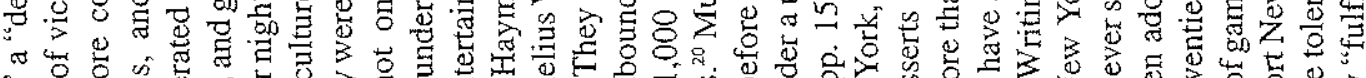

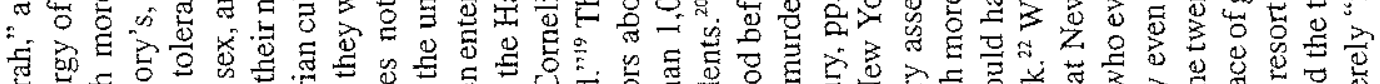

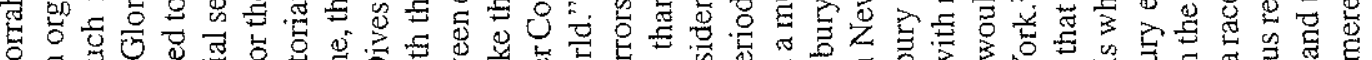

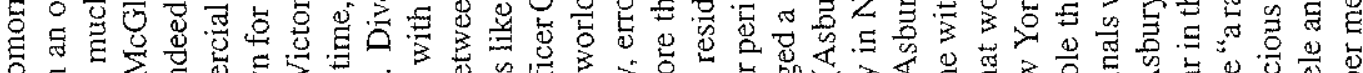

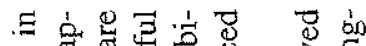

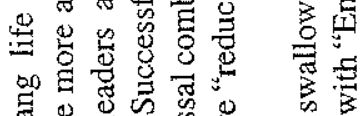

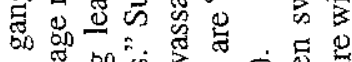

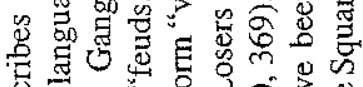
要

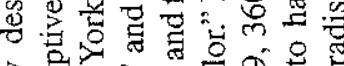

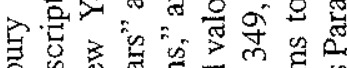

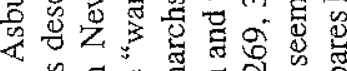

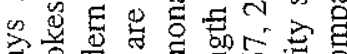

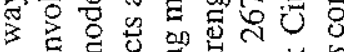
Q)

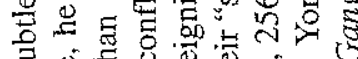
क $巳 巳$

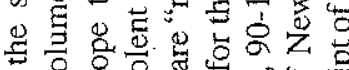

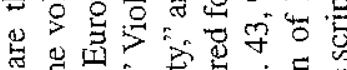

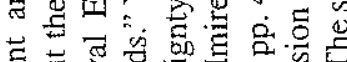

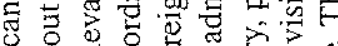

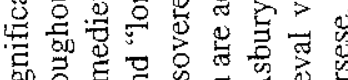

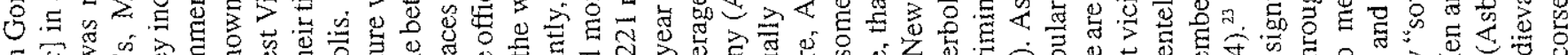

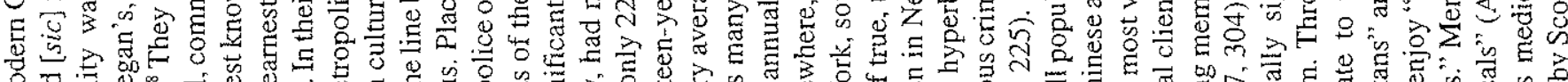

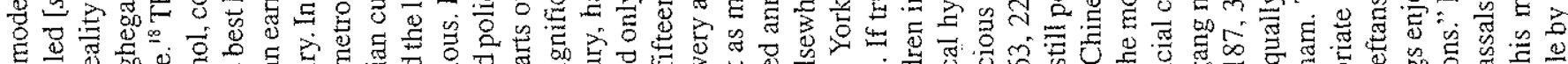

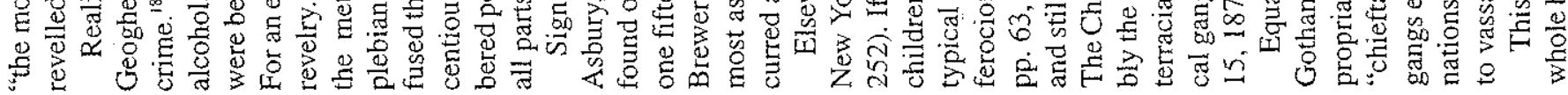




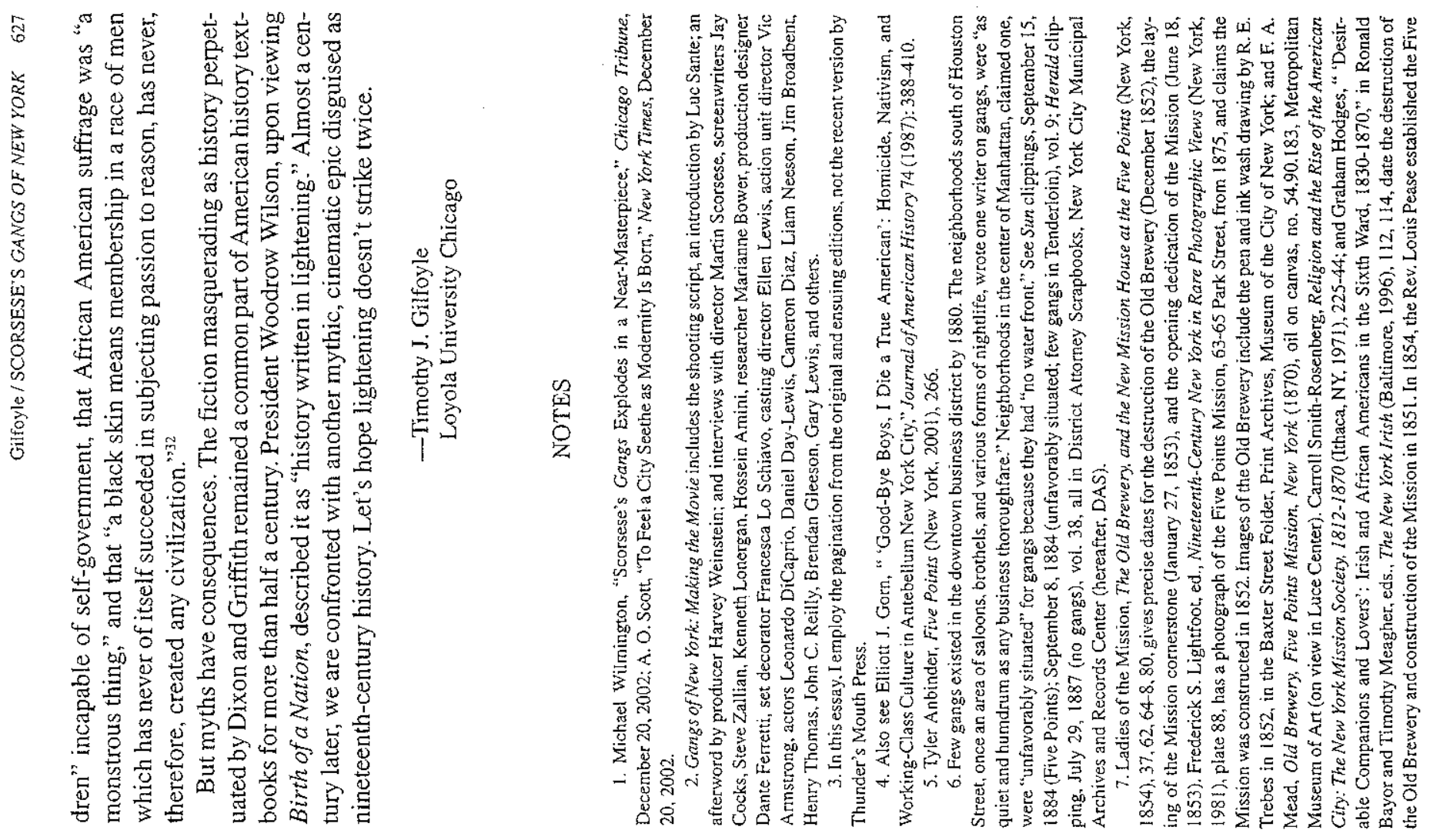

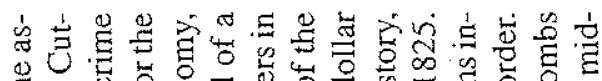

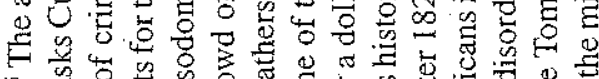

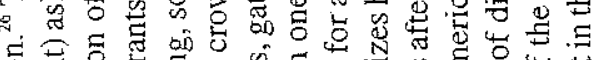

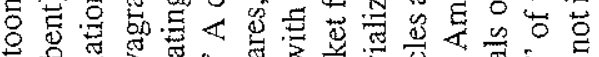

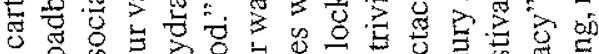

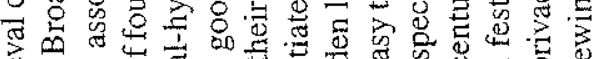

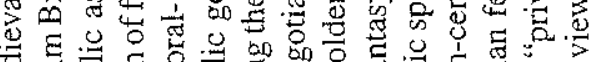

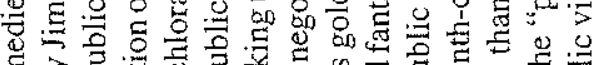

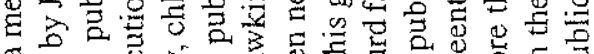

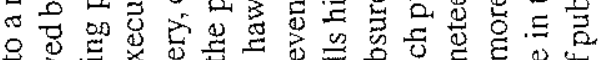

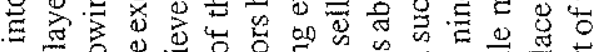

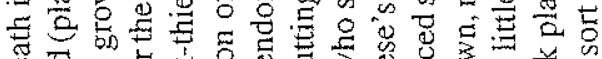

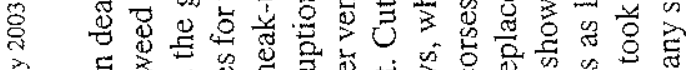

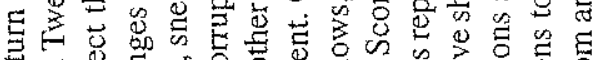

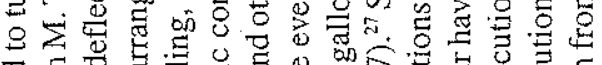

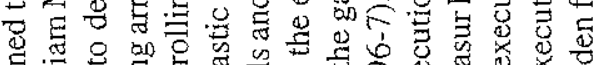

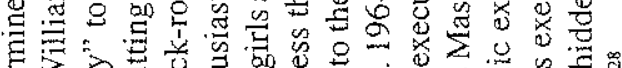

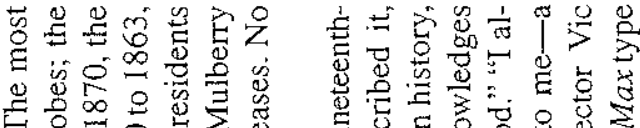

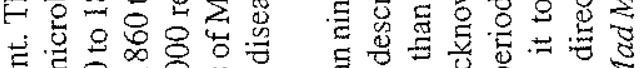

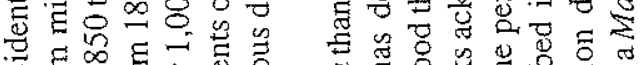

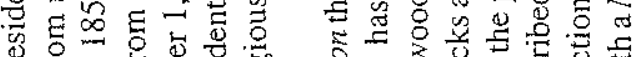

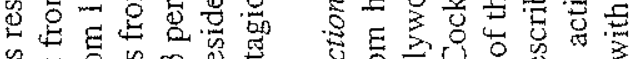

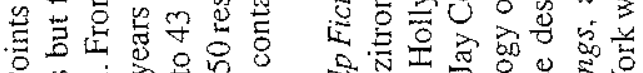

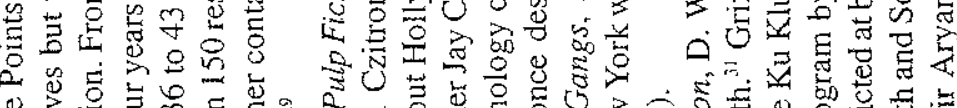

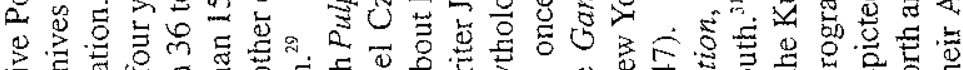

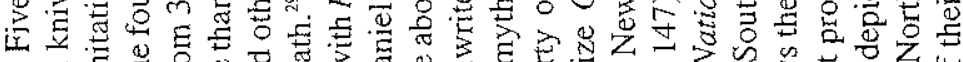

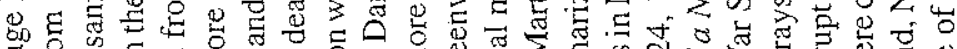

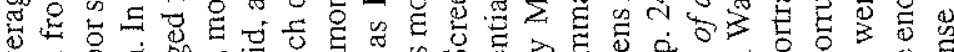

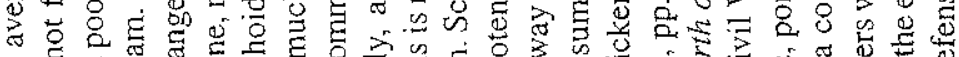

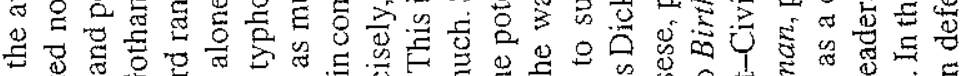

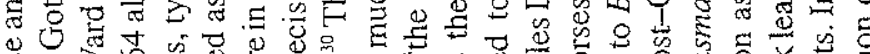

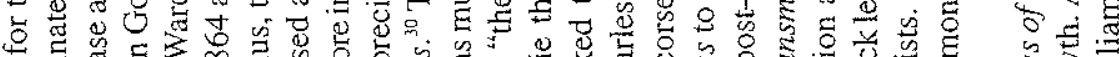
0.

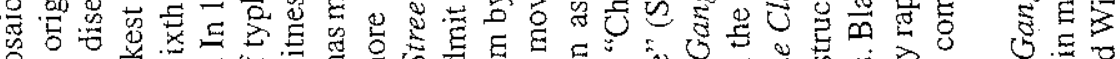

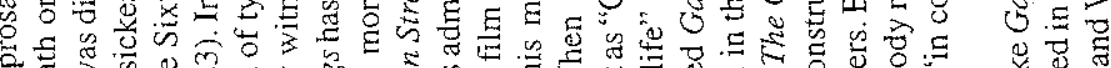

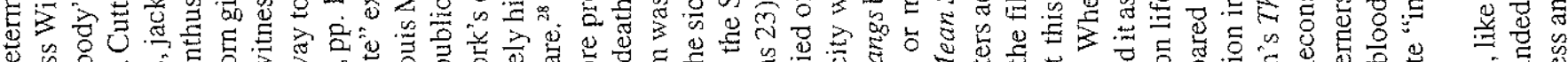

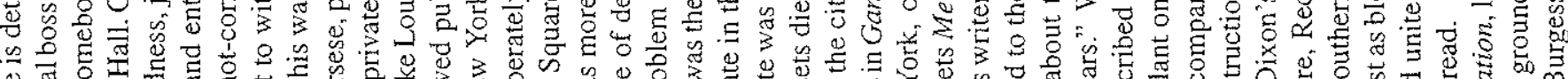

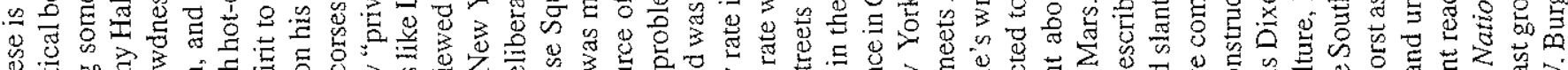

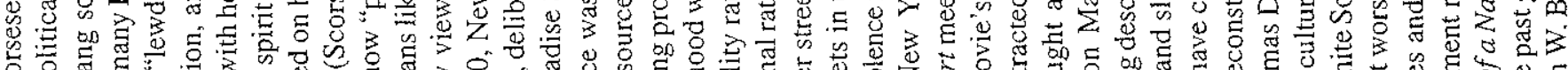

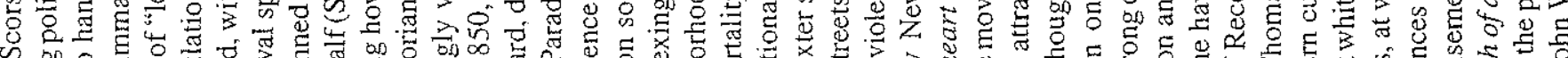

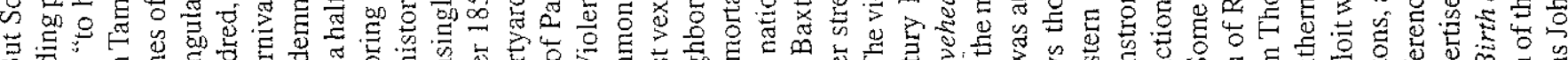

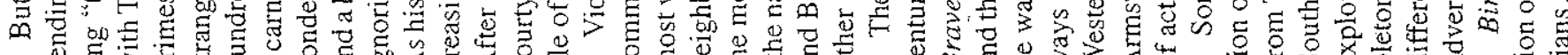

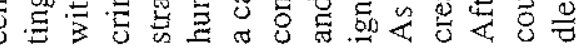




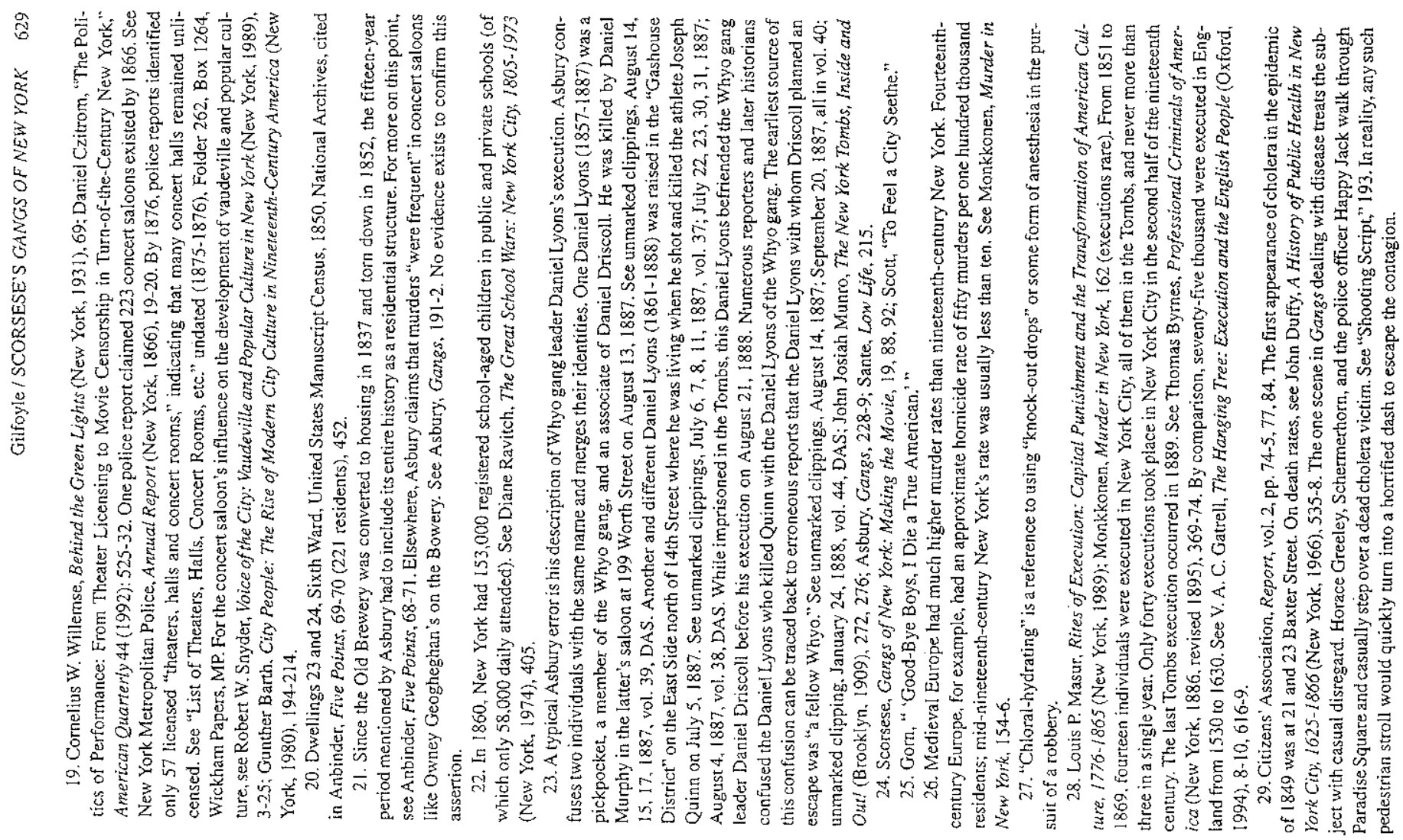

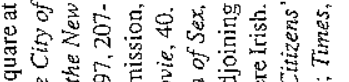

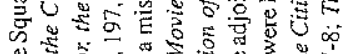

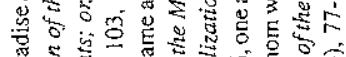

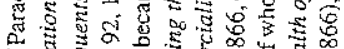
它

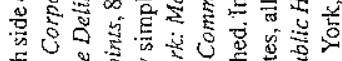

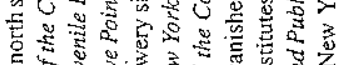

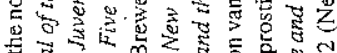

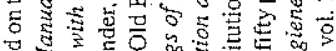

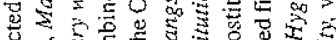

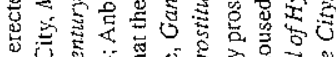

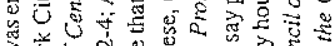

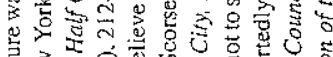

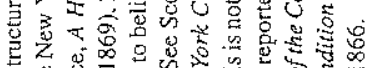

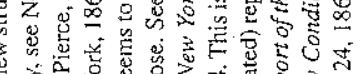

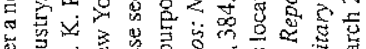

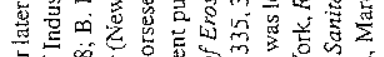

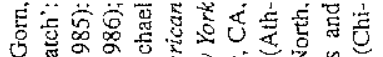

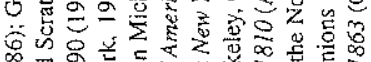

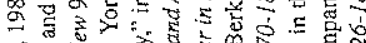

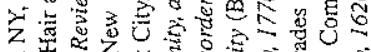

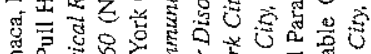

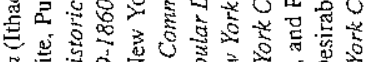

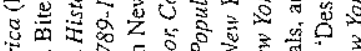

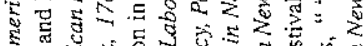

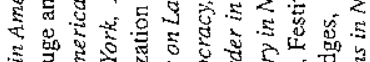

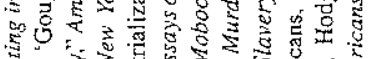

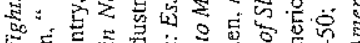

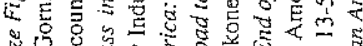

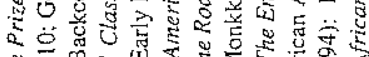

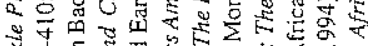

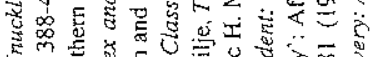

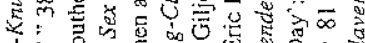

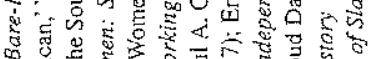

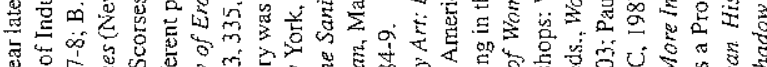

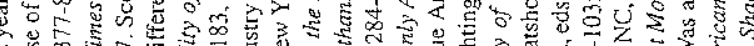

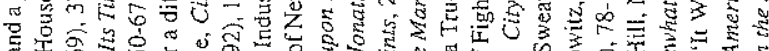

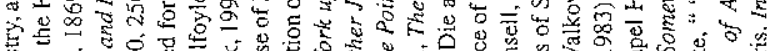

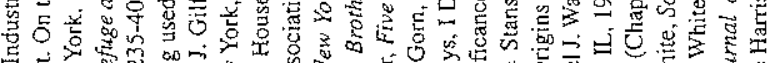

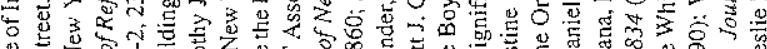

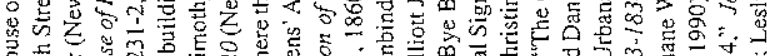

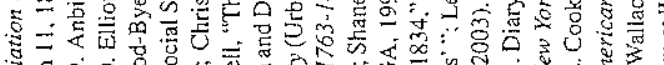

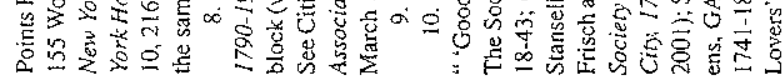

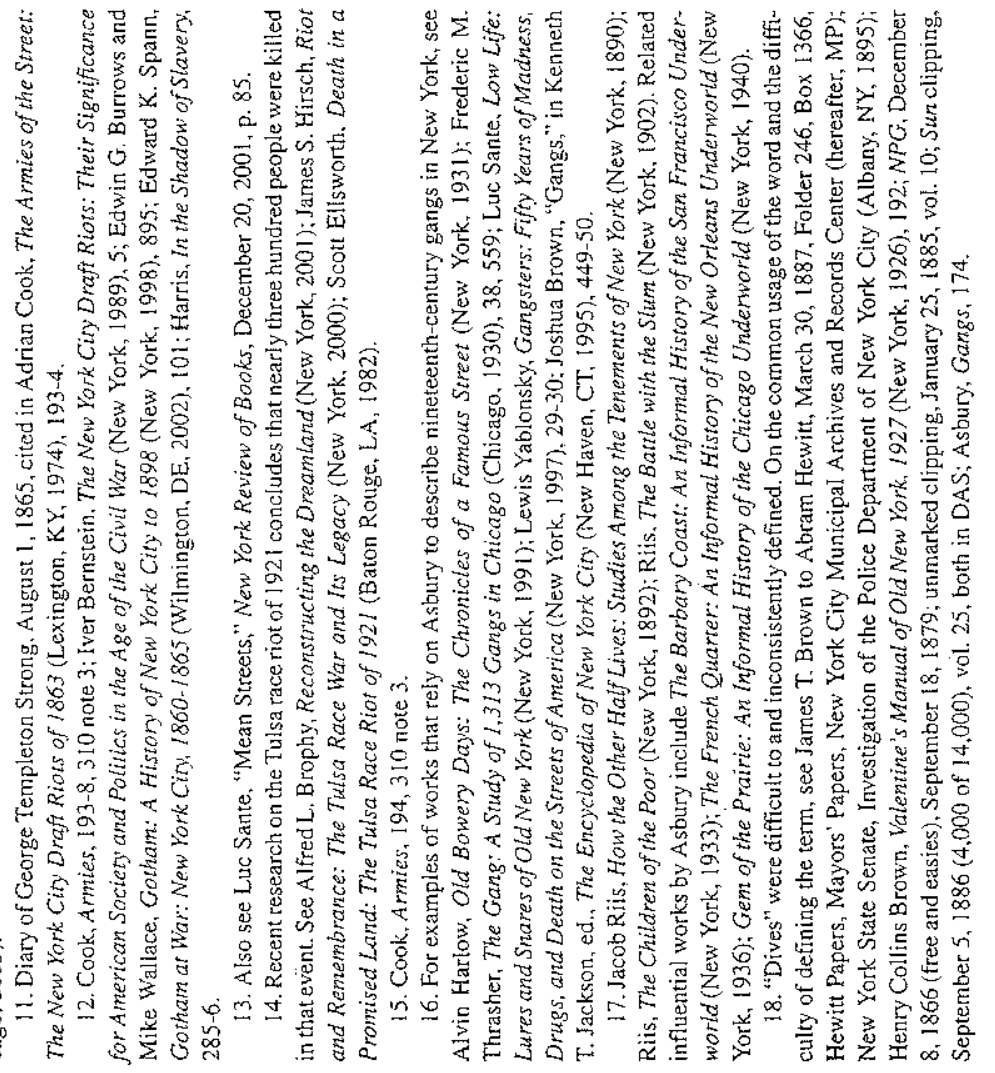



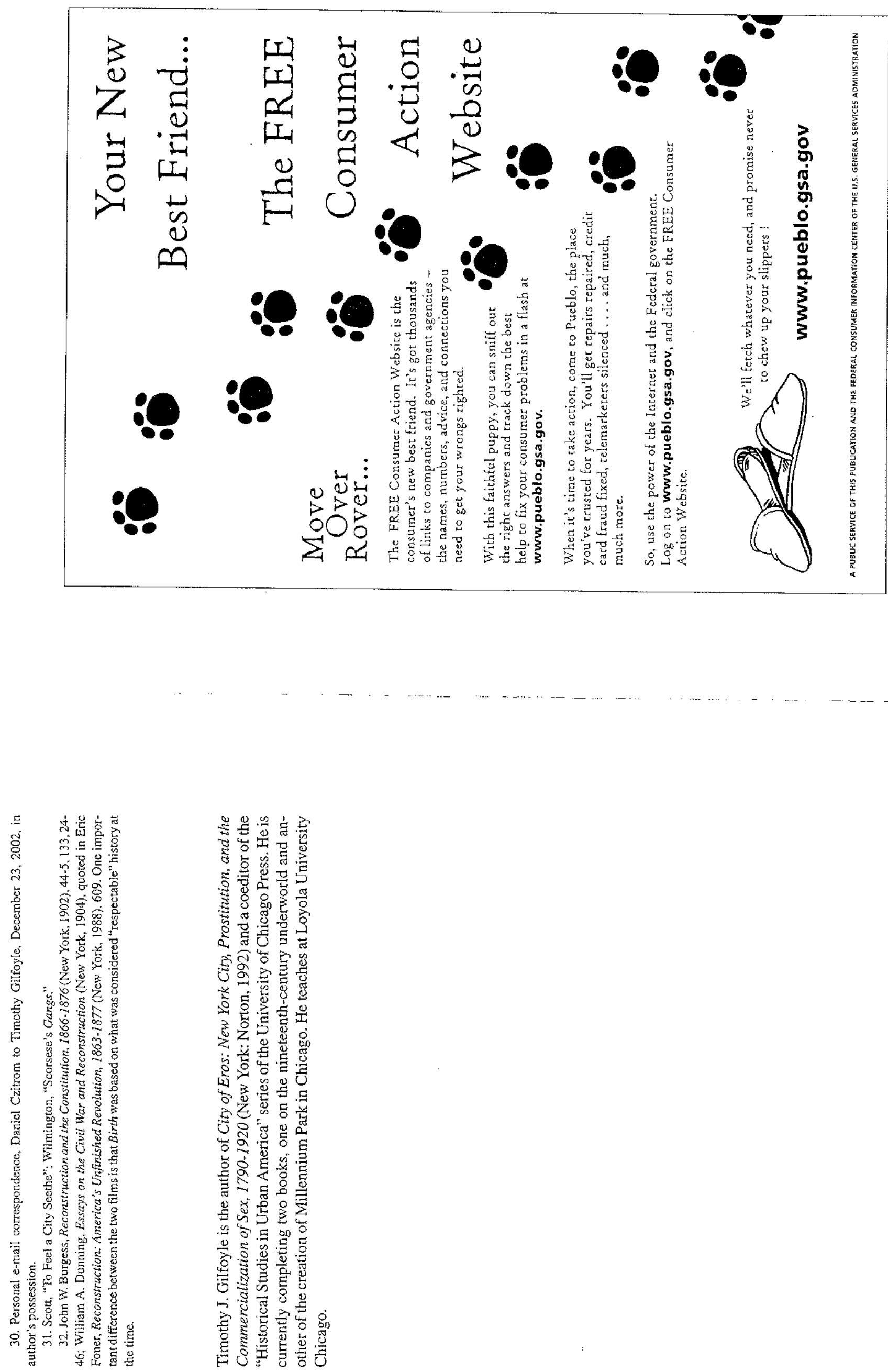